centre, as in Victoria, is essential for optimal care ${ }^{9}$ and recent data from Denmark ${ }^{10}$ indicate a much better survival among patients attending a specialist clinic compared with those looked after by their local paediatrician, as happens for most children in England and Wales.

The results of this study indicate a need for further research in England and Wales into the reasons why the death rate in cystic fibrosis seems to be substantially higher there than in Victoria, Australia, and also, probably, in major referral centres in North America.

We thank the OPCS for access to data on childhood death from cystic fibrosis in England and Wales, and Dr Alison Macfarlane for help in analysing the data available on 'multiple cause coding'.

\footnotetext{
References

${ }^{1}$ Danks DM, Allan J, Anderson CM. A genetic study of fibrocystic disease of the pancreas. Ann Hum Genet 1965;28:323-56.

2 Allan JL, Robbie M, Phelan PD, Danks DM. The incidence and presentation of cystic fibrosis in Victoria 1955-1978, Aust Paediatr J 1980;16:270-3.
}

${ }^{3}$ Hall BD, Simpkiss MJ. Incidence of cystic fibrosis in Wessex. J Med Genet 1968;5:262-5.

${ }^{4}$ Armitage P. Statistical methods in medical research. Oxford: Blackwell Scientific Publications, 1971:410-4.

5 Danks DM, Allan JL, Phelan PD, Chapman C. Mutations at more than one locus may be involved in cystic fibrosisevidence based on first cousin data and direct counting of cases. Am J Hum Genet 1983; in press.

6 Oppenheimer EH, Esterly JR. Pathology of cystic fibrosis. Review of the literature and comparison with 146 autopsied cases. In: Rosenberg HS, Bolande RP, eds. Perspectives in paediatric pathology. Vol. 2. Chicago and London: Year Book, 1975:241-78.

7 Phelan PD, Landau LI, Olinsky A. Cystic fibrosis. Respiratory illness in children. 2nd ed. Oxford: Blackwell Scientific Publications, 1982:239-93.

${ }^{8}$ Corey ML. Longitudinal studies in cystic fibrosis. In: Sturgess JM, ed. Perspectives in cystic fibrosis. Toronto: Cystic Fibrosis Foundation, 1980:246-55.

9 Stern RC, Boat TF, Doershuk CF, et al. Course of cystic fibrosis in 95 patients. $J$ Pediatr 1976:89:406-11.

10 Nielsen OH, Schiotz PO. Cystic fibrosis in Denmark in the period 1945-1981. Evaluation of centralised treatment. Acta Paediatr Scand [Suppl] 1982;301:107-19.

Correspondence to Professor P D Phelan, Department of Paediatrics, Royal Children's Hospital, Parkville, Victoria 3052, Australia.

Received 21 July 1983

\title{
Pancuronium bromide induced joint contractures in the newborn
}

\author{
S K SINHA AND M I LEVENE \\ Neonatal Unit, Leicester University Medical School
}

SUMMARY We report three infants paralysed with pancuronium bromide as an adjunct to mechanical ventilation, who developed multiple joint contractures. In two term infants, gentamicin and phenobarbitone given together with pancuronium may have potentiated its effect, and in one preterm infant contractures, which became more severe after paralysis, were present at birth.

Pancuronium bromide (Pavulon) is a nondepolarising muscle relaxant increasingly used in neonatal intensive care units to facilitate the management of infants undergoing mechanical ventilation. We report here the development of joint contractures in three of 13 infants, seen over an 8 month period, who received this drug as an adjunct to ventilatory treatment.

\section{Patients}

Between July 1982 and February 1983, 13 infants admitted to the Leicester Royal Infirmary Neonatal Intensive Care Unit received intermittent bolus injections of pancuronium bromide $(0.1 \mathrm{mg} / \mathrm{kg}$ body weight per dose as needed) to minimise spontaneous movement and facilitate mechanical ventilation. During the course of ventilation regular chest physiotherapy and four hourly changes in posture were undertaken in all infants. Details of these infants are shown in the Table. Three infants aged between 5 hours and 3 days died. Of the remaining 10 , three developed contractures described in more detail below.

Case 4. Pancuronium bromide was started at 3 hours and continued until 27 hours of age in one girl. Initially she had a full range of joint movements. Seizures were treated with phenobarbitone, which was started on day 2 . On day 8 she was noted to have limited extension of both knees and restricted abduction of both hips. Intensive passive stretching exercises were instituted but at 4 months of age full extension in the right knee was still limited by 20 degrees. 
Table Details of infants receiving pancuronium bromide

\begin{tabular}{|c|c|c|c|c|c|c|}
\hline $\begin{array}{l}\text { Case } \\
\text { No }\end{array}$ & $\begin{array}{l}\text { Gestational } \\
\text { age (weeks) }\end{array}$ & $\begin{array}{l}\text { Birthweight } \\
(g)\end{array}$ & Diagnosis & $\begin{array}{l}\text { Duration of } \\
\text { paralysis }\end{array}$ & $\begin{array}{l}\text { Number of } \\
\text { doses }\end{array}$ & Other drugs used \\
\hline 1 & 37 & 2800 & RDS & 3 days & 9 & Penicillin and gentamicin \\
\hline 2 & 42 & 2680 & MAS & 3 days & 11 & Penicillin and gentamicin \\
\hline 3 & 33 & $18(x)$ & RDS & 4 days & 11 & Penicillin and gentamicin \\
\hline $4^{*}$ & 39 & 2620 & MAS & 2 days & 3 & $\begin{array}{l}\text { Penicillin and gentamicin. tolazoline. } \\
\text { phenobarbitone. dopamine }\end{array}$ \\
\hline 5 & 35 & 2070 & RDS & 2 days & 4 & Penicillin and gentamicin \\
\hline $6+$ & 26 & 1040 & Asphyxia & 5 hours & 1 & Penicillin and gentamicin \\
\hline $7+$ & 36 & $25(0)$ & $\begin{array}{l}\text { Diaphragmatic } \\
\text { Hernia }\end{array}$ & 3 days & 5 & $\begin{array}{l}\text { Penicillin and gentamicin, tolazoline. } \\
\text { dopamine }\end{array}$ \\
\hline $8 \dagger$ & 30 & 1310 & RDS, DIC & 2 days & 3 & Penicillin and gentamicin \\
\hline $9^{*}$ & 32 & 1610 & RDS & 6 hours & 1 & Penicillin and gentamicin \\
\hline 10 & 33 & 1680 & RDS & 2 days & 8 & None \\
\hline $11^{*}$ & 43 & 3920 & MAS & 8 days & 41 & $\begin{array}{l}\text { Penicillin and gentamicin. tolazoline, } \\
\text { phenobarbitone, dopamine, solbutamol }\end{array}$ \\
\hline 12 & 35 & $21(0)$ & RDS & 1 day & 2 & None \\
\hline 13 & 28 & 1240 & RDS & 2 days & 2 & Penicillin and gentamicin \\
\hline
\end{tabular}

* Infants who developed contractures; + died.

RDS = respiratory distress syndrome; $\mathrm{MAS}=$ meconium aspiration syndrome; $\mathrm{DIC}=$ disseminated intravascular coagulation

Case 9. At birth this girl was noted to have some limited extension of the right elbow and left knee joint which was thought to be due to oligohydramnios as a result of prolonged rupture of membranes. Her hip joints were fully mobile. Ventilation began at birth and continued for 19 hours. Only one dose of pancuronium bromide was given and this produced paralysis for a period of 6 hours. Subsequently she was found to have limitation of abduction of both hip joints and 30 degree contractures of both knees. At age 2 months her hip abduction was still limited as was full extension of the knee joints, despite regular passive physiotherapy.

Case 11. A boy was ventilated from 18 hours of age for a total of 7 days because of meconium aspiration syndrome. The first dose of pancuronium bromide was given at 21 hours, seizures having been observed shortly before this. He was treated with a loading dose of phenobarbitone $(20 \mathrm{mg} / \mathrm{kg})$ followed by maintenance doses $(6 \mathrm{mg} / \mathrm{kg} /$ day $)$ for two weeks. Joint movements were full at birth but at 10 days of age contractures were noted affecting the knee joints (30 degrees in the left and 20 degrees in the right) together with limited abduction of the right hip. At 3 months of age there was still limitation of full extension in both knee joints despite regular physiotherapy.

\section{Discussion}

Joint contractures present at birth are commonly associated with congenital muscular dystrophy and fetal compression syndrome, but the true incidence of joint contractures developing postnatally in nor- mal newborn infants is unknown. We report here three infants who developed severe contractures after neuromuscular blockade with pancuronium bromide, and in whom a full range of movements had not returned by age 2 to 3 months.

The unusual occurrence of acquired contractures in these three infants led us to consider possible causes. During the 8 month period described here there had been an increase in our use of pancuronium bromide but we do not believe that contractures associated with its use are confined to our hospital. Although there have been no cases in the published reports of pancuronium bromide induced contractures occurring in the newborn, we have seen sporadic cases in other neonatal units.

Animal studies have shown that immobilisation of fetal animals by muscle relaxants given to the mother produce joint malformation. ${ }^{1}$ In humans maternal paralysis for status epilepticus ${ }^{2}$ and tetanus ${ }^{3}$ have been associated with joint contractures in the neonate. There is thought to be a vulnerable period for joint development, and immobilisation during this time is associated with a high risk of joint contractures. Our findings do not, however, support this. Four of the infants reported here were born at 32 weeks' gestation and below and only one developed contractures. This infant was born with joint deformities that became more extensive, and she may have been unusually sensitive to neuromuscular blockade.

It has been shown that pancuronium bromide induced paralysis may be potentiated by both aminoglycoside antibiotics ${ }^{4}$ and phenobarbitone, ${ }^{5}$ both of which were used in the two mature infants developing contractures. Our infants were only given pancuronium bromide when respiratory effort 
was felt to impede adequate ventilation and spontaneous limb movement was not noted. It is possible that the combination of gentamicin and phenobarbitone may have potentiated limb mobility and that it was the lack of normal movements and tone which predisposed to joint contractures. We suggest that careful and regular passive movements of all major joints be made during the course of paralysis and that infants treated with aminoglycosides or phenobarbitone, or both, be observed with particular care for the early detection of joint contractures.

We thank Mrs Robinson and the Physiotherapy Department for advice and help.
References

${ }^{1}$ Drachman DB, Coulombre AF. Experimental clubfoot and arthrogryposis multiplex congenita. Lancet 1962;ii:523-6.

2 Older PO, Harris JM. Placental transfer of tubocurarine. Br J Anaesth 1968;40:459-63.

3 Vago RH. Arthrogryposis following treatment of maternal tetanus with muscle relaxants. Arch Dis Child 1970;45:277-9.

4 Warner WA, Sanders E. Neuromuscular blockade associated with gentamicin therapy. JAMA 1971;215:1153-4.

5 Miller RD. Factors affecting the action of muscle relaxants. In: Katz RL, ed. Muscle relaxants. New York: American Elsevier, 1975:163-91.

Correspondence to Dr M I Levene, Neonatal Unit, Department of Child Health, Leicester University Medical School, Leicester.

Received 27 September 1983.

\title{
Intrathoracic extramediastinal cystic hygroma
}

\author{
M G PIKE, A J WOOD, B CORRIN, AND J O WARNER \\ Departments of Paediatrics and Lung Pathology, Brompton Hospital and Cardiothoracic Institute, London
}

SUMMARY A case of intrathoracic, extramediastinal cystic hygroma presenting with pneumonia in a 6 year old boy is described.

Cystic hygroma usually presents in the neck or axilla. Intrathoracic cystic hygromas are rare, usually situated in the mediastinum, and generally present in adult life.

\section{Case report}

A 6 year old boy with a cough, fever, and left sided pleuritic chest pain was admitted to hospital and treated with antibiotics and physiotherapy for left sided pneumonia and pleurisy. After rapid improvement he was discharged on day 6 . Chest radiographs at follow up two weeks after discharge showed a persistent capacity confluent with the left hemidiaphragm, although the boy was asymptomatic (Figure). No comparison could be made with earlier radiographs as the boy had not undergone $x$ ray examination before pneumonia. Apart from some dullness to percussion and reduced breath sounds at the left base, there were no abnormal findings on examination.

Barium meal and follow through excluded a diaphragmatic hernia. Bronchoscopy showed some superior displacement and slight compression of the left main bronchus. At thoracotomy a lobulated cystic tumour measuring $9 \mathrm{~cm} \times 4 \mathrm{~cm}$ was found lying between the diaphragm and the undersurface of the left lower lobe. Roughly triangular in shape with its apex arising anteriorly between the diaphragm and the pericardium, it passed posteriorly over the diaphragm and was attached to the chest wall by an adhesion resembling a cord. There were inflammatory adhesions to the lung and diaphragm, both of which were otherwise normal.

The mass comprised one large and many smaller cysts containing either discoloured blood or gelatinous material. The cyst walls consisted of thick fibrous tissue with a few nondescript flattened lining cells. They contained many focal aggregates of lymphocytes and plasma cells and showed prominent foreign body giant cells around collections of cholesterol crystals. There was a thin layer of smooth muscle in the walls of some of the cysts. The lesion was identified as a cystic hygroma.

\section{Discussion}

Intrathoracic cystic hygromas outside the mediastinum are particularly rare, and diagnosis requires the exclusion of a number of other conditions. Hydatid cysts, teratomatous dermoid cysts, and embryonal cysts of respiratory and alimentary origin all have a distinctive lining and are easily differentiated. A more difficult differential diagnosis in the mediasti- 